\title{
Classification and staging of thymoma
}

\author{
Till Markowiak ${ }^{1}$, Hans-Stefan Hofmann ${ }^{1,2}$, Michael Ried $^{1}$ \\ ${ }^{1}$ Department of Thoracic Surgery, University Medical Center Regensburg, Regensburg, Germany; ${ }^{2}$ Department of Thoracic Surgery, Hospital \\ Barmherzige Brüder Regensburg, Regensburg, Germany \\ Contributions: (I) Conception and design: T Markowiak, M Ried; (II) Administrative support: All authors; (III) Provision of study materials or \\ patients: None; (IV) Collection and assembly of data: None; (V) Data analysis and interpretation: None; (VI) Manuscript writing: All authors; (VII) \\ Final approval of manuscript: All authors. \\ Correspondence to: Michael Ried, MD. Department of Thoracic Surgery, University Medical Center Regensburg, Franz-Josef-Strauß-Allee 11, D-93053 \\ Regensburg, Germany. Email: michael.ried@ukr.de.
}

\begin{abstract}
The appropriate therapy and prognosis of patients with thymic malignancies is decisively influenced by the local extent and dissemination of the tumor. For this reason, a staging system that reflects these factors is essential. Mainly the Masaoka-Koga classification, which was introduced in 1994, has been applied for this purpose. The rarity of thymic malignancies makes it difficult not only to establish internationally standardized diagnostics and treatment, but also to progress staging. Besides, efforts were made to adapt the classification into a tumor-node-metastasis-based (TNM) system for standardization with the staging of other tumor entities. The 2017 published 8th edition of the TNM Classification of Malignant Tumors introduced several adjustments based on a proposal of the International Association for the Study of Lung Cancer (IASLC) and the International Thymic Malignancy Interest Group (ITMIG). Compared to the Masaoka-Koga classification, surgically good resectable tumor involvements like pericardium, mediastinal fat or mediastinal pleura have been shifted to lower stages. Thus, even more than in MasaokaKoga classification, tumors are basically divided into completely resectable and thus surgically treatable tumors (stage I, II, IIIA) and advanced stages (stage IIIB, IVA and IVB) that require multimodal therapy.
\end{abstract}

Keywords: Thymoma; thymic carcinoma (TC); tumor staging; hyperthermic intrathoracic chemotherapy

Submitted May 21, 2020. Accepted for publication Aug 10, 2020.

doi: $10.21037 /$ jtd-2019-thym-01

View this article at: http://dx.doi.org/10.21037/jtd-2019-thym-01

\section{Introduction}

Thymoma and thymic carcinomas (TC) are rare tumor entities that occur mostly in the fourth to sixth decade of life $(1,2)$. They represent only about $0.2-1.5 \%$ of all malignancies, which makes it difficult to identify and establish optimal strategies in staging and treatment $(3,4)$. As with other tumors, the extent and spreading of thymic malignancies play a central role in terms of the patients' prognosis. In 1981, Masaoka et al. first identified local expansion, infiltration of neighboring structures and hematogenic or lymphogenic dissemination as major factors regarding survival. These criteria were used to assign the patients to one of four clinical stages (5). A later modification by Koga et al. in 1994 resulted in the widely known and long-time used Masaoka-Koga staging system (6).

Growing clinical expertise and innovative multimodal treatment concepts led to a reevaluation about the impact of certain tumor localizations $(4,7)$. Also, there were efforts to transfer the Masaoka-Koga classification into a tumor-nodemetastasis (TNM)-based system. For this reason, Yamakawa et al. first introduced an adaption of the Masaoka-Koga classification into a TNM system (8). In the recent years there have been new developments in classification and staging of thymoma and TC (9). The 8th edition of the TNM Classification of Malignant Tumors published in 2017 introduced several adjustments based on a proposal of the International Association for the Study of Lung Cancer (IASLC) and the International Thymic Malignancy Interest 


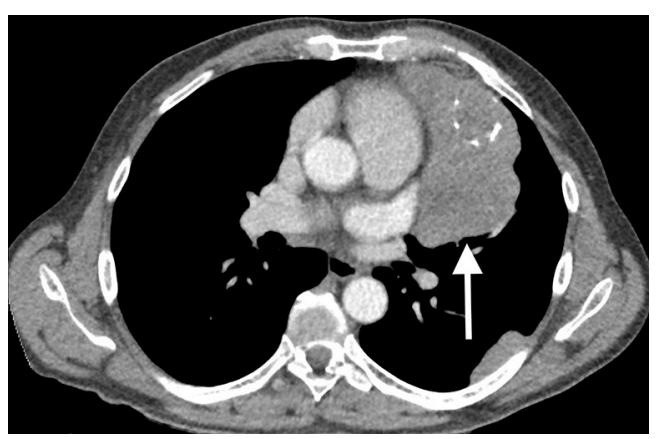

Figure 1 Axial cut at the level of the truncus pulmonalis in contrast-enhanced computed tomography. A large tumorous mass of the anterior mediastinum is visible (white arrow). It shows a locally advanced thymoma with also pleural dissemination (stage IVA) (WHO B1).

Group (ITMIG) (10,11).

This article is intended to provide a brief overview of the current status of staging, as well as the impact of the new developments on stage-adapted therapy in especially advanced thymic malignancies.

\section{Diagnostic evaluation}

The contrast-enhanced computed tomography (CT) still represents the gold standard in the diagnosis and evaluation of thymic tumors (Figure 1). For better tissue differentiation, a magnetic resonance imaging (MRI) may also be recommended $(4,12)$. However, both procedures cannot reliably detect early stages of cardiac, pericardial, pleural or vascular infiltration (12). In this regard, a MRI with cine sequences can provide useful information by exposing tissue mobility between the tumor and surrounding structures during cardiac action and by that improve preoperative staging and the decision making for surgery (13). An Indium-111-octreotide scan should be considered in patients with advanced thymic tumors who might be indicated for induction therapy or who have not responded to standard chemotherapy as they may benefit from octreotide therapy (14).

Due to modern imaging techniques, a preoperative biopsy is not obligatory in resectable tumors and is usually only used to exclude malignant lymphoma or germ cell tumors (15). Thus, the identification and preoperative staging and therefore the decision about which therapy to initiate is decisively based on radiological imaging (16).
Table 1 Stage grouping (descriptor definitions in Table 2) (10)

\begin{tabular}{lccc}
\hline Stage & T & N & M \\
\hline I & T1 & No & M0 \\
II & T2 & No & M0 \\
IIIA & T3 & No & M0 \\
IIIB & T4 & No & M0 \\
IVA & T any & N1 & M0 \\
& T any & No/N1 & M1a \\
IVB & T any & N2 & M0/M1a \\
& T any & N any & M1b \\
\hline
\end{tabular}

\section{Classification}

In the TNM-based classification system, the T descriptor represents the local extent and infiltration into neighboring structures (9). A tumor is classified with the highest attributable $\mathrm{T}$ level, regardless of whether there is an involvement of structures with lower T levels (10). Surgical resectability and the resulting postoperative resection (R)status represent the main prognostic factors for patients with thymoma or TC $(17,18)$. The $\mathrm{T}$ descriptor therefore is of greatest significance. Since thymic malignanciesexcept TC—-show low metastatic potential, the $\mathrm{N}$ and $\mathrm{M}$ descriptors are only relevant in defining the most advanced stage IV (Table 1) (1,19).

Compared to the long time applied Masaoka-Koga definition, stage I of the new TNM classification was extended from encapsulated tumors only to tumors even involving the mediastinal fat or mediastinal pleura. Both localizations of infiltration can be treated very easily by radical surgical resection (20). Tumors that involve the pericardium now form TNM stage II (formerly transcapsular lesions). By that, these mostly well resectable tumor localizations were now moved from the in terms of resectability highly heterogeneous Masaoka-Koga stage III into TNM stages I and II. The influence of both localizations on long-term survival is proved to be rather low (10).

The newly TNM stage III is now subdivided into A and $\mathrm{B}$, mainly describing thymic tumors with primarily mediastinal invasion of infiltration of adjacent structures. Stage IIIA is formed by potentially resectable tumors with involvement of e.g. lung, brachiocephalic vein, superior vena cava, chest wall, phrenic nerve and pulmonary vessels. 
Table 2 Comparison of Masaoka-Koga and TNM classification (main changes highlighted) $(6,9,10,21)$

\begin{tabular}{|c|c|c|}
\hline Stage & Masaoka-Koga & IASCL/ITMIG \\
\hline II & $\begin{array}{l}\text { A: microscopic transcapsular invasion. } \\
\text { B: macroscopic invasion into thymic or } \\
\text { surrounding fatty tissue, or grossly adherent to } \\
\text { but not breaking through mediastinal pleura or } \\
\text { pericardium }\end{array}$ & $\begin{array}{l}\text { T2 NO M0. T2: pericardial involvement. NO: no nodal involvement. MO: no } \\
\text { metastatic pleural, pericardial, or distant sites }\end{array}$ \\
\hline III & $\begin{array}{l}\text { Macroscopic invasion into neighboring organ (i.e., } \\
\text { pericardium, great vessel, or lung) }\end{array}$ & $\begin{array}{l}\text { A: T3 NO M0. T3: invasion of the lung, brachiocephalic vein, superior vena } \\
\text { cava, chest wall, phrenic nerve, hilar (extrapericardial) or pulmonary vessels. } \\
\text { N0: no nodal involvement. M0: no metastatic pleural, pericardial, or distant } \\
\text { sites. B: T4 NO M0. T4: invasion of the aorta, arch vessels, main pulmonary } \\
\text { artery, myocardium, trachea, or esophagus. NO: no nodal involvement. M0: } \\
\text { no metastatic pleural, pericardial, or distant sites }\end{array}$ \\
\hline
\end{tabular}

On the other side, stage IIIB is defined by an infiltration of the larger arterial vessels (aorta), myocardium, trachea, and oesophagus. Involvement of anterior (perithymic) lymph nodes was moved from Masaoka-Koga IVB to TNM stage IVA, which still includes mainly patients with pleural or pericardial dissemination. Thymic malignancies with involvement of deep intrathoracic or cervical lymph nodes and pulmonary intraparenchymal nodule or distant organ metastasis are extremely rare and classified as TNM stage IVB (Tables 1 and 2) (4). Especially the infestation of thoracic lymph nodes plays a bigger role in the proposed TNM staging system compared to the Masaoka-Koga classification. However, the significance of lymph node metastases remains not clear und also the optimal extend of lymph dissection in patients with thymic malignancies is not established yet $(19,22)$. Further studies regarding the manifestation of thymic tumor cells in mediastinal lymph nodes are warranted (23).

\section{Stage-adapted therapy}

There are no internationally accepted guidelines in the diagnosis and therapy of thymic malignancies. However, good studies exist on established as well as innovative therapy regimes (4). Except for stage IVB tumors, surgery remains the preferred treatment. A complete resection is usually feasible in stage I and II, so that usually no further therapy is indicated for these tumors after complete radical resection, except for patients with TC (Table 3). These early stages of thymoma in particular show low rates of recurrence and a good long-term survival. The possibility of a complete resection (R0) is considered the most important prognostic factor in the literature with regard to long-term outcome $(25,26)$.

Advanced and invasive thymoma require a multimodal approach for better local tumor control (27-29). In contrast to stages I and II, therapy of stages III and IV is still controversially debated. Besides surgery, therapeutic options include induction chemotherapy, adjuvant chemotherapy and/or postoperative radiotherapy (suitable for WHO B2-3, TC, R1/2 tumors) $(4,13,18,21,24)$. Hyperthermic intrathoracic chemotherapy (HITOC) can also be offered to patients with pleural seeding (stage IVA) after surgical cytoreduction of the pleural tumor dissemination (Table 3). In HITOC, the pleural cavity is perfused with a heated solution containing cisplatin over a period of approximately one hour after pleurectomy/ decortication (P/D) or extrapleural pneumonectomy to kill remaining tumor cells (30). Lung-sparing pleural tumor resection (P/D) should be the preferred therapy due to lower postoperative morbidity and mortality. The few existing studies focusing on this procedure demonstrated 
Table 3 Expert opinion on stage-adapted imaging and therapy of thymoma $(4,13,18,21,24)$

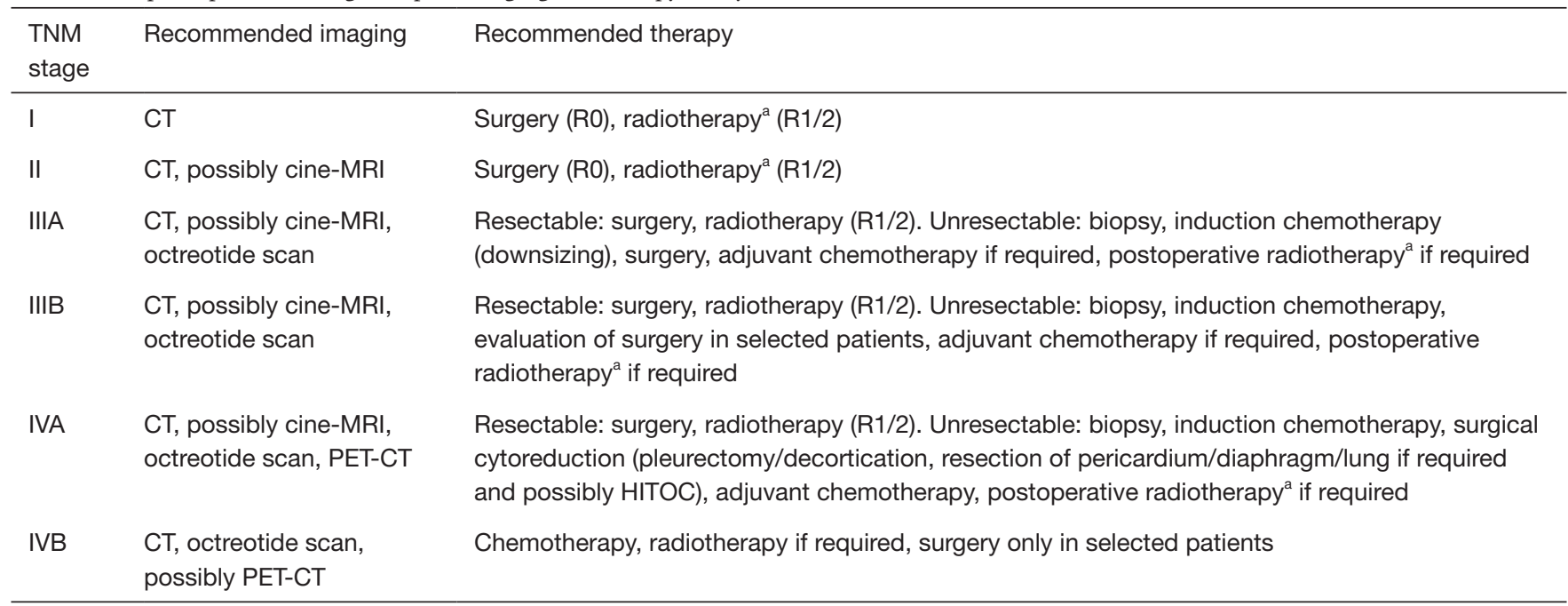

a, suitable for WHO B2-3, TC, R1/2. CT, computed tomography; HITOC, hyperthermic intrathoracic chemotherapy; MRI, magnetic resonance imaging; $\mathrm{PET}$, positron-emission tomography.

encouraging results in terms of morbidity, mortality, longterm and recurrence-free survival $(31,32)$.

Multimodality treatments and innovative procedures result in the TNM stage not necessarily correlating with the estimated survival of the patient. One reason for this might be that advanced stages III and IV were probably underrepresented in the latest analysis (10). Thus, for example stage IVA patients might even have better prognosis than stage III patients (9). While stage III tumors may infiltrate vitally essential structures and thus require radiotherapy and systemic treatment, pleural metastases (stage IVA) are often accessible to surgical cytoreduction and innovative local approaches such as HITOC. Even selected patients with pleural recurrence of thymoma might be suitable for surgery, but always in a multimodality treatment concept.

\section{Conclusions}

(I) The 8th edition of the TNM Classification of Malignant Tumors contains several novel adjustments regarding the staging of thymic malignancies.

(II) Compared to the Masaoka-Koga classification, surgically good resectable tumor localizations like pericardium, mediastinal fat or mediastinal pleura have been shifted to lower stages.

(III) Surgical therapy remains the first choice of treatment in all stages if the chance for a complete resection is provided.

(IV) Advanced stages infiltrate vitally essential mediastinal structures or show pleural dissemination, and therefore require multimodal therapies including radical surgical resection, induction or adjuvant chemotherapy and/or postoperative radiotherapy.

(V) Innovative treatment strategies in stage IVA patients might offer even better survival rates than in locally advanced stage III patients.

\section{Acknowledgments}

Funding: None.

\section{Footnote}

Provenance and Peer Review: This article was commissioned by the Guest Editors (Dragana Jovanovic and Semra Bilaceroglu) for the series "Thymoma" published in fournal of Thoracic Disease. The article was sent for external peer review organized by the Guest Editors and the editorial office.

Conflicts of Interest: All authors have completed the ICMJE uniform disclosure form, available at: http://dx.doi. org/10.21037/jtd-2019-thym-01. The series "Thymoma" was commissioned by the editorial office without any funding or sponsorship. The authors have no other conflicts 
of interest to declare.

Ethical Statement: The authors are accountable for all aspects of the work in ensuring that questions related to the accuracy or integrity of any part of the work are appropriately investigated and resolved.

Open Access Statement: This is an Open Access article distributed in accordance with the Creative Commons Attribution-NonCommercial-NoDerivs 4.0 International License (CC BY-NC-ND 4.0), which permits the noncommercial replication and distribution of the article with the strict proviso that no changes or edits are made and the original work is properly cited (including links to both the formal publication through the relevant DOI and the license). See: https://creativecommons.org/licenses/by-nc-nd/4.0/.

\section{References}

1. Detterbeck FC, Parsons AM. Thymic tumors. Ann Thorac Surg 2004;77:1860-9.

2. Lindenmann J, Fink-Neuboeck N, Pichler M, et al. Stagebased treatment for thymoma in due consideration of thymectomy: a single-center experience and comparison with the literature. World J Surg Oncol 2015;13:303.

3. Smit EF. Thymic malignancies. Ann Oncol 2008;19 Suppl 7:vii309-12.

4. Ried M, Marx A, Gotz A, et al. State of the art: diagnostic tools and innovative therapies for treatment of advanced thymoma and thymic carcinoma. Eur J Cardiothorac Surg 2016;49:1545-52.

5. Masaoka A, Monden Y, Nakahara K, et al. Follow-up study of thymomas with special reference to their clinical stages. Cancer 1981;48:2485-92.

6. Koga K, Matsuno Y, Noguchi M, et al. A review of 79 thymomas: Modification of staging system and reappraisal of conventional division into invasive and non-invasive thymoma. Pathology International 1994;44:359-67.

7. Ried M, Neu R, Schalke B, et al. Radical surgical resection of advanced thymoma and thymic carcinoma infiltrating the heart or great vessels with cardiopulmonary bypass support. J Cardiothorac Surg 2015;10:137.

8. Yamakawa Y, Masaoka A, Hashimoto T, et al. A tentative tumor-node-metastasis classification of thymoma. Cancer 1991;68:1984-7.

9. Ried M, Eicher MM, Neu R, et al. Evaluation of the new TNM-staging system for thymic malignancies: impact on indication and survival. World J Surg Oncol 2017;15:214.
10. Detterbeck FC, Stratton K, Giroux D, et al. The IASLC/ ITMIG Thymic Epithelial Tumors Staging Project: proposal for an evidence-based stage classification system for the forthcoming (8th) edition of the TNM classification of malignant tumors. J Thorac Oncol 2014;9:S65-72.

11. Brierley JD, Gospodarowicz MK, Wittekind C. TNM Classification of Malignant Tumours. Wiley, 2016.

12. Marom EM. Imaging thymoma. J Thorac Oncol 2010;5:S296-303.

13. Ried M, Hnevkovsky S, Neu R, et al. Impact of Surgical Evaluation of Additional Cine Magnetic Resonance Imaging for Advanced Thymoma with Infiltration of Adjacent Structures: The Thoracic Surgeon's View. Thorac Cardiovasc Surg 2017;65:244-9.

14. Pettit L, El-Modir A. The role of somatostatin analogues in the treatment of advanced malignant thymomas: case report and review of the literature. $\mathrm{Br} \mathrm{J}$ Radiol 2011;84:e7-10.

15. Ruffini E, Van Raemdonck D, Detterbeck F, et al. Management of thymic tumors: a survey of current practice among members of the European Society of Thoracic Surgeons. J Thorac Oncol 2011;6:614-23.

16. Benveniste MF, Rosado-de-Christenson ML, Sabloff BS, et al. Role of imaging in the diagnosis, staging, and treatment of thymoma. Radiographics 2011;31:1847-61; discussion 1861-3.

17. Cardillo G, Carleo F, Giunti R, et al. Predictors of survival in patients with locally advanced thymoma and thymic carcinoma (Masaoka stages III and IVa). Eur J Cardiothorac Surg 2010;37:819-23.

18. Venuta F, Anile M, Diso D, et al. Thymoma and thymic carcinoma. Eur J Cardiothorac Surg 2010;37:13-25.

19. Huang J. A new staging system for thymoma--will it improve outcomes? J Thorac Cardiovasc Surg 2016;151:20-2.

20. Wright CD. Extended resections for thymic malignancies. J Thorac Oncol 2010;5:S344-7.

21. Detterbeck FC, Nicholson AG, Kondo K, et al. The Masaoka-Koga stage classification for thymic malignancies: clarification and definition of terms. J Thorac Oncol 2011;6:S1710-6.

22. Hwang Y, Park IK, Park S, et al. Lymph Node Dissection in Thymic Malignancies: Implication of the ITMIG Lymph Node Map, TNM Stage Classification, and Recommendations. J Thorac Oncol 2016;11:108-14.

23. Viti A, Bertolaccini L, Terzi A. What is the role of lymph nodal metastases and lymphadenectomy in the surgical treatment and prognosis of thymic carcinomas 
and carcinoids? Interact Cardiovasc Thorac Surg 2014;19:1054-8.

24. Kirzinger L, Boy S, Marienhagen J, et al. Octreotide LAR and Prednisone as Neoadjuvant Treatment in Patients with Primary or Locally Recurrent Unresectable Thymic Tumors: A Phase II Study. PLoS One 2016;11:e0168215.

25. Regnard JF, Magdeleinat P, Dromer C, et al. Prognostic factors and long-term results after thymoma resection: a series of 307 patients. J Thorac Cardiovasc Surg 1996;112:376-84.

26. Lardinois D, Rechsteiner R, Lang RH, et al. Prognostic relevance of Masaoka and Muller-Hermelink classification in patients with thymic tumors. Ann Thorac Surg 2000;69:1550-5.

27. Ried M, Guth H, Potzger T, et al. Surgical resection of thymoma still represents the first choice of treatment. Thorac Cardiovasc Surg 2012;60:145-9.

28. Kondo K, Monden Y. Therapy for thymic epithelial tumors: a clinical study of 1,320 patients from Japan. Ann

Cite this article as: Markowiak T, Hofmann HS, Ried M. Classification and staging of thymoma. J Thorac Dis 2020;12(12):7607-7612. doi: 10.21037/jtd-2019-thym-01
Thorac Surg 2003;76:878-84; discussion 884-5.

29. Kattach H, Anastasiadis K, Cleuziou J, et al. Transsternal thymectomy for myasthenia gravis: surgical outcome. Ann Thorac Surg 2006;81:305-8.

30. Sugarbaker DJ, Gill RR, Yeap BY, et al. Hyperthermic intraoperative pleural cisplatin chemotherapy extends interval to recurrence and survival among low-risk patients with malignant pleural mesothelioma undergoing surgical macroscopic complete resection. J Thorac Cardiovasc Surg 2013;145:955-63.

31. Ambrogi MC, Korasidis S, Lucchi M, et al. Pleural recurrence of thymoma: surgical resection followed by hyperthermic intrathoracic perfusion chemotherapydagger. Eur J Cardiothorac Surg 2016;49:321-6.

32. Ried M, Potzger T, Braune N, et al. Cytoreductive surgery and hyperthermic intrathoracic chemotherapy perfusion for malignant pleural tumours: perioperative management and clinical experience. Eur J Cardiothorac Surg 2013;43:801-7. 